\title{
Developing a Measure of Virtual Community Citizenship Behavior
}

\section{Luman Yong*}

Minnesota State University, Mankato, USA

E-mail: Lmy1636@gmail.com

\section{Daniel Sachau}

Minnesota State University, Mankato, USA

E-mail: daniel.sachau@mnsu.edu

\author{
Andrea Lassiter \\ Minnesota State University, Mankato, USA \\ E-mail: andrea.lassiter@mnsu.edu \\ *Corresponding author
}

\begin{abstract}
This study examines the kinds of behaviors that constitute virtual community citizenship behaviors (VCCB) and tests three factors that may influence community members' willingness to engage in VCCB. More specifically, the authors propose a multi-dimensional VCCB construct (altruism, civic virtue, consciousness, courtesy, and sportsmanship) and three antecedents of VCCB (affective commitment, structural embeddedness and membership tenure). Four dimensions including altruism, civic virtue, courtesy and loyalty emerged as a result of behavioral examples collection from SMEs using critical incident technique and a VCCB survey with 19 Likert type items reflecting the behavioral examples within each dimension was created. Data was collected from an online discussion forum (The Grad Cafe) to address the research questions of this study. Results indicate that affective commitment was a significant predictor of the virtual community citizenship behaviors. A research agenda for studying VCCB is presented.
\end{abstract}

Keywords: Virtual Community; Citizenship Behaviors; Measure Development

Biographical notes: Luman Yong studied Applied Psychology as her undergraduate major and went on to complete the Master of Arts degree in Industrial/Organizational Psychology at Minnesota State University, Mankato. Her research interests include learning motivation in virtual community and citizenship behavior.

Dr. Daniel Sachau is Professor and Director of the Graduate Program in I/O Psychology at Minnesota State University. He is also Director of the Organizational Effectiveness Research Group consulting practice at MSU.

Dr. Andrea Lassiter is an Associate Professor in the Graduate Program of I/O Psychology at Minnesota State University, Mankato. Her research interests and previous publications include topics such as computer-supported collaborative learning and team training. 


\section{Introduction}

A virtual community is the gathering of people in an online "space" where they connect, communicate and get to know each other better over time (Boetcher, Duggan \& White, 2002). The origin of this term is attributed to Howard Rheingold. He defined a virtual community as a social aggregation that emerges from the Net when enough people carry on those public discussions long enough, with sufficient human feeling, to form webs of personal relationships in cyberspace (Rheingold, 1993). This definition highlights the importance of social interactions among community members for an online space to function as a community.

The majority of studies on virtual communities have focused on knowledge sharing. For a virtual community to sustain over time, it is important to ensure the willingness of community members to share knowledge and exchange information. However, the source of motivation for people to join and stay in a virtual community not only arises from the desire to exchange information, but from the need for affiliation, social support and affirmation (Donath, 1996). Hence, in addition to knowledge sharing, the sustainability of a virtual community is contingent upon how well the socio-emotional needs of community members are fulfilled in the community.

For this reason, such interactive behaviors as addressing other community members' issues, showing social support for others who are in need, and trying to fulfill others' needs by providing positive affirmation are integral to the sustainability of a virtual community. These efforts serve as "glue which holds collective endeavors together" (Brief \& Motowidlo, 1986, p. 712). Along with knowledge sharing, these behaviors are spontaneous in nature and in the aggregate benefit the successful functioning of a virtual community. Therefore, they can be viewed as organizational citizenship behaviors in a virtual community setting, or virtual community citizenship behaviors (VCCB).

Despite the importance of virtual community citizenship behavior, little empirical research has been conducted to investigate what behaviors constitute virtual community citizenship, nor has there been much research on the factors that influence community members' willingness to engage in social interactions other than knowledge sharing. Therefore, a research focus shift from knowledge sharing to virtual community citizenship behavior is necessary for a better understanding of the sustainability of virtual communities. To fill this gap, we develop a measure for assessing VCCB and we examine individual differences that may affect the expression of those behaviors.

\section{Literature Review}

\subsection{Definitions of VCCB-Like Constructs}

There is a large body of literature on organizational citizenship behavior (OCB). The origin of this construct can be traced back to Barnard (1938) who noted that the effective functioning of an organization not only depends on formal structure and control, but also relies on the "willingness of persons to contribute efforts to the cooperative system" ( $p$. 83). The concept was further developed by Katz (1964) who defined citizenship behaviors as those spontaneous behaviors that exceed the role requirements for the organizational effectiveness, including cooperative gestures, actions protective of system and behavior that enhances the external image of the organization. Today, the most popular definition of OCB is attributed to Dennis Organ (1988). He defines OCB as 
"individual behavior that is discretionary, not directly or explicitly recognized by the formal reward system, and that in aggregate promotes the effective functioning of the organization" (p. 4).

Organ suggests there are three critical components that are essential to this construct. First, OCB is discretionary and is essentially a matter of personal choice. Therefore, its omission is not generally punishable. Second, citizenship behaviors do not necessarily result in recompense, which means the rewards associated with OCB are indirect and uncertain as opposed to behaviors performed under a formal reward system. Finally, citizenship behaviors contribute to the overall organizational effectiveness over time and across situations. Hence, even though not every single OCB will make a difference in organizational outcomes, the overall effect will be positive. For instance, people who frequently offer help to their co-workers will contribute to the effective functioning of their organization in the long term (Organ, 1997).

In traditional organizations, OCBs include offering support or help to coworkers, attending meetings on behalf of the organization, and volunteering for activities to create a positive image of the organization. Similarly, there is a class of cooperative and helping behaviors in a virtual community that resembles organizational citizenship behaviors, such as addressing others' questions issues posted online, participating in community building activities and being considerate about one's action toward other community members. As with OCB, the focus of these spontaneous behaviors is on the collective rather than the individual self. Hence, such behaviors that foster the effective functioning of a virtual community can be viewed as analogous to organizational citizenship behavior.

Citizenship behaviors in the virtual community have been conceptualized in slightly different ways depending on the type of virtual community; however, all definitions involve the core values of $\mathrm{OCB}$ - discretionary behavior that has a positive effect on the organization functioning and is performed without the intent of gaining formal rewards (Chiu, Wang \& Fang, 2009; Yu \& Chu, 2007; Bateman, Gray \& Butler, 2006; Kang, Lee, Lee \& Choi, 2007). For instance, Chiu et al. (2009) studied an online professional community and defined virtual community citizenship as a member's beneficial behaviors that taken together promote the effective functioning of the virtual community. Research by $\mathrm{Yu}$ and $\mathrm{Chu}$ (2007) maintained that online gamers are acting conscientiously as team members, tolerating the risk of no return, and providing useful information to prevent problems from arising for other team members. In a research article by Bateman et al. (2006), community citizenship behaviors refer to those activities that are essential to community functioning, including welcoming new members, being involved in community building activities, recognizing other community members who contribute informative messages, discouraging inappropriate behaviors, and preventing exploitation of members. Consistent with these studies, Kang et al. (2007) introduced the concept of online community voluntary behavior (OCVB). According to this research, OCVB refers to all positive community-relevant behaviors of individual members.

Drawing upon the concept of $\mathrm{OCB}$ and the relevant literature on virtual communities, we define virtual community citizenship behavior (VCCB) as the spontaneous, voluntary behaviors with a positive influence on the effective functioning of a virtual community.

\subsection{Dimensions of VCCB-Like Constructs}

$\mathrm{OCB}$ in online or virtual communities has been conceptualized as consisting of different dimensions from study to study. Wiertz, Ruyter \& Streukens (2003) propose that 
commercial virtual community citizenship behavior is an aggregate construct composed of three underlying dimensions. Helping refers to those voluntary actions that help another member with a problem. Civic virtue deals with a class of behaviors that shows a person's active involvement in community building activities driven by concerns about the life of the community. Sportsmanship indicates the willingness to tolerate less than ideal circumstance without complaining. Kang et al. (2007) offered a different threedimensional online community voluntary behavior (OCVB) construct composed of community commitment, loyalty and social participation.

Among those VCCB-like constructs, most of the dimensions are adapted from the five-dimension OCB construct developed by Organ (1988), which encompasses altruism (discretionary behaviors aimed at helping a co-worker with work-related problems), conscientiousness (consists of behaviors that go beyond the minimum role requirements of the organization), sportsmanship (refers to the willingness to tolerate the inevitable inconveniences and impositions of work without complaining), courtesy (deals with consulting with others before taking action), and civic virtue (is concerned with keeping up with matters that affect the organization). A meta-analysis study showed that this taxonomy of OCB was established as stable across studies (LePine, Erez \& Johnson, 2002).

Because virtual community is a relatively new concept and there are a variety of taxonomies of VCCB behaviors, we elected to collect critical incidents of VCCBs and use these incidents to see which themes or dimensions emerge. We predicted that the themes of the incidents would include 1) altruism (voluntary behaviors aimed at helping other community members with their problems), 2) conscientiousness (discretionary actions beyond the minimum requirements of the virtual community), 3) civic virtue (responsible, constructive participation, and involvement in the community building activities), 4) courtesy (being considerate of others and prevent problems from arising) and 5) sportsmanship (willingness to tolerate the inevitable inconveniences).

\subsection{Antecedents of Citizenship Behaviors}

The majority of studies on virtual community focused on identifying the factors that influence members' willingness to share knowledge. As mentioned, OCB in virtual community is mainly built around knowledge sharing behaviors and most researchers reached consensus on the importance of knowledge sharing as a typical altruistic behavior that benefits the effective functioning of a virtual community (Yu \& Chu, 2007; Chiu et al., 2009; Bateman el al., 2006). Because participation in virtual community is voluntary, it is tempting to think that all participation is a form of citizenship behavior. However, the alternative to active participation is commonly referred to as lurking. Lurkers simply read the work of other members and derive benefits without actually contributing to the group (Nonnecke \& Preece, 1999). So what factors influence virtual community members' willingness to engage in citizenship behaviours?

$\mathrm{Yu}$ and Chu (2007) examined members of an online gaming community and identified three antecedents of altruistic behavior including cohesiveness, affection similarity and leader-member exchange. The degree of cohesiveness influence group members' desire to contribute to the team. Affection influenced the extent to which members are committed to a group. Leader-member exchange determined the level of members' willingness to reciprocate the help they obtained from the team. As this study was conducted in an online gaming community, the factors that influence community 
members' willingness to engage in helping behaviors were focused on team building dynamics.

A study by Oded and Chen (2008) using the virtual community Flicker attempted to identify factors that are associated with users' photo sharing in a social computing community. Their research drew upon motivation theories as well as network analysis and found users' who are more committed to the community and highly embedded in the community tend to share the most.

Chiu et al. (2009) found in open professional virtual communities that job satisfaction is a robust attitudinal predictor of citizenship behavior. In a virtual community, the feeling of satisfaction resulting from interacting with other members within the virtual community enhances members' desire to participate in communityoriented behaviors. In addition, the authors considered the perceived hedonic value or utilitarian value benefits of knowledge sharing. Hedonic value focuses on the multisensory, fantasy, emotive and enjoyment-related values derived from the knowledge sharing experience, consisting of playfulness, social interaction, self-worth, challenge, and community attachment. Utilitarian value is concerned with the functional, instrumental and practical values derived from the knowledge sharing experience, including reputation, reciprocity, career advancement, and reflective learning. These perceived value serve as component in forming the antecedents of citizenship behaviors in the professional virtual community.

These studies provide insights into what factors influence online or virtual community members' altruistic sharing behaviors that are mainly focused on knowledge sharing behaviors. In next section, three hypotheses are developed in order to further previous research by shifting the focus from knowledge sharing to a broader view of a multi-dimensional VCCB construct. In any virtual community, a proportion of community members tend to be highly involved in spontaneous community-oriented behaviors. To some extent, they are the key contributors who influence the effective functioning of a virtual community. Hence, it would be worthwhile to identify the factors that drive top contributors to engage in virtual community citizenship behaviors so that organizers of a virtual community can adopt corresponding strategies to enlarge this group of civic minded members. While there is consensus on the existence of VCCB-like behaviors, there is much less convergence on the antecedents of these behaviors. In this study, we take a closer look at the factors that may influence members' willingness to engage in those citizenship behaviors. We focus specifically on three potential antecedents of citizenship behavior: affective commitment, structural embeddedness and membership tenure.

\section{Hypothesis Development}

\subsection{Affective Commitment}

First, we hypothesize that members' affective commitment will positively influence their willingness to engage in virtual community citizenship behaviors. Affective commitment is a highly cited factor as an antecedent of OCB (Organ \& Ryan, 1995; Schappe 1998; Wasko \& Faraj, 2005). According to Meyer and Allen (1997), affective commitment refers to the employee's emotional attachment to the organization. Employees who are affectively committed to an organization are more likely to identify themselves with the organization and enjoy the membership. In virtual communities, organizational 
commitment has been found to be positively related to sharing behaviors and other cooperative behaviors. For instance, Li, Browne \& Wetherbe (2006) found that commitment was positively related to the amount of time members spent at a website over a given time period. Moreover, community members' tend to feel a sense of responsibility to engage in helping behaviors (e.g. knowledge sharing) as their commitment to the community increases (Wasko \& Faraj, 2005). Similarly, Kang et al., (2007) showed that members with strong commitment to the community tend to be more concerned about the fate of their community and engage in community-relevant behaviors. Affective commitment that emphasizes the strength of bonds with the company as a whole influences the extent to which community members are willing to engage in spontaneous behaviors favorable to the community. Thus, it seems we expect that the level of community members' affective commitment will positively influence their willingness to engage in virtual community citizenship behaviors.

Hypothesis 1: The higher a member's level of affective commitment, the higher the member's willingness to engage in virtual community citizenship behaviors will be.

\subsection{Structural Embeddedness}

In addition to affective commitment, we hypothesize that community members' level of structural embeddedness will positively influence their willingness to engage in virtual community citizenship behavior. Structural embeddedness describes the impersonal configuration of linkages between people and can be operationalized as the number of ties a user has to others in a network (Nahapiet and Ghoshal, 1998; Wasko \& Faraj, 2005). In other words, this construct reflects the extent to which a person is connected to others within a social network. In a virtual community, it is the interactions among community members that knit the social fabric.

Researchers suggested that individuals who are highly structurally embedded in a social network are more likely to comply with norms and engage in pro-social behaviors than members who are not embedded (Rogers \& Kincaid, 1981). Based on the insights gained from previous study, the present study attempts to link the level of structural embeddedness with community members' willingness to engage in virtual community citizenship behaviors.

Hypothesis 2: The higher a member's level of structural embeddedness, the higher the member's willingness to engage in virtual community citizenship behaviors will be.

\subsection{Membership Tenure}

Membership tenure is theorized as an antecedent of virtual community citizenship behaviors. Previous studies suggest that socialization in a particular setting involves learning those social behaviors considered appropriate in a certain norm, and therefore a period of time of lurking in an online community can be a phase needed for a member to observe and internalize those behaviors (Yeow, Johnson \& Faraj, 2006). In other words, it takes time for a community member to start to actively participate in those communityoriented behaviors. In addition, a study by Wasko \& Faraj (2005) suggested that members with longer membership tenure in online community of practice are more likely to know what area and how their expertise can be useful and are better able to share knowledge with others. 
Another study by Pettit, Donohue \& Cieri (2004) offered a fresh perspective as to how career stage relates to people's willingness to engage in organizational citizenship behaviors. More specifically, the later stages of an individual's career tend to be associated with the feeling of being needed and of reciprocating what they obtained from the community. In this stage, satisfaction may result from helping others, a sense of being useful and serving the community. Similarly, there are a series of sequential stages that a member may go through from an outsider to an insider in a virtual community. A model proposed by Lave and Wenger (1991) suggested that there are five stages in a learning community, including peripheral (i.e. Lurker), inbound (i.e. Novice), insider (i.e. Regular), boundary (i.e. Leader) and outbound (i.e. Elder). The trajectories require time to go through, and thus there is a possibility that longer membership tenure is associated with a tendency to give back to that virtual community by engaging in virtual community citizenship behaviors. Therefore, it is possible to see membership tenure positively influence members' willingness to engage in virtual community citizenship behaviors.

Hypothesis 3: The longer a member's membership tenure, the higher the member's willingness to engage in virtual community citizenship behaviors will be.

In sum, we propose a multi-dimensional VCCB construct including altruism, civic virtue, consciousness, courtesy and sportsmanship. We suggest that affective commitment, structural embeddedness, and membership tenure are antecedents of virtual community citizenship behavior. In the next section, we discuss the development of a measure VCCB.

\section{Method}

\subsection{Item Development}

We administered a critical incidence survey and asked members of various virtual communities to describe specific incidents of citizenship behaviors. The survey was posted in six online discussion forums (MacRumors, BlackBerryForums.com, BigSoccer.com, Pregnancy.org, BaseballFever.com and Proz.com). Participants read:

A virtual community is a social network of individuals who interact through specific media, potentially crossing geographical boundaries in order to pursue mutual interests or goals. In virtual communities, people can hold conversations in the form of posted messages. Like the virtual community MacRumors, it is an online community where people can share thoughts and information regarding many Apple-related issues, as well as talk to other Mac users about other community related issues. Do you happen to be actively involved in any virtual community?

Participants who indicated that they were actively involved in a virtual community read another questions:

Coming from two Latin words meaning "with gifts," the term community suggests a general sense of altruism, reciprocity, and beneficence that comes from working together. People who join a virtual community are not only looking for information, they are also looking for affiliation, support and affirmation. 
Virtual community citizenship behaviors (VCCB) are defined as a member's discretionary behaviors that promote the effective functioning of the virtual community. Sometimes people at virtual community may go beyond passive information viewing and actually interact with other community members to address their posted issues or engage in some community related events to foster its development.

Think about yourself and other community members you interacted with in the past. Please list as many examples as you can remember of these kinds of "virtual community citizenship behaviors".

50 common critical incidents were generated by 32 subject matter experts (SMEs) who were active virtual community members. Next the items were classified into four general categories: 1) Altruism, 2) Civic Virtue, 3) Courtesy, and 4) Loyalty by a new group of SMEs (students from Industrial and Organizational Psychology Program). Items were retained for each subscale if $70 \%$ of SMEs agreed with their placement. Conscientiousness could not be distinguished from civic virtue so we elected to combine them into one dimension: civic virtue. None of the incidents involved Sportsmanship as Organ defined it. The incidents did, however, include loyalty (broadcasting the benefits of the community) which is a category proposed as a taxonomy of citizenship behavior in the research by Kang et al. (2007).

\subsection{Survey Development}

We created 19 Likert type items reflecting the behavioral examples within each category. We gave the survey to 55 members of the Grad Cafe (http://forum.thegradcafe.com/). The Grad Cafe forum is an online community for graduate and potential graduate students who help each other with the trials and tribulations of applying to graduate school. In this forum, virtual community citizenship behaviors are common among community members, including addressing others' concerns related to graduate school application, offering suggestions when other forum users are in need of advice, and showing emotional support for others.

Participants were asked to estimate the extent to which they agree with each statement. The answers were scored on a seven-point Likert scale ranging from (1) Strongly Disagree to (7) Strongly Agree. Please refer to Table 1 for the items in the VCCB survey.

Participants also completed a seven item affective commitment scale based on Allen \& Meyers' (1990) Affective Commitment Scale. Participants responded to the items using a five-point Likert scale where (1) corresponded with strongly disagree and (5) corresponded with strongly agree. People who score high on the scale personally identify with the community and have a strong emotional attachment to the group. Please refer to Table 2 for the items in Affective Commitment Scale.

All of the subscale totals were then divided by the number of items in the subscale thus returning the subscale total to its original 5 or 7 point scale. In addition, participants completed two biodata items. Structural embeddedness was operationalized as how many friends participants have in the virtual community. Tenure was operationalized as how long participants have been in the virtual community. 
Table 1. Subscales and Items for VCCB Measure

Altruism

1. I offer honest and well-intentioned advice to other community members.

2. I follow up on other members' questions to see if there is any information I can pass on as soon as I get it.

3. I assist other members in finding solutions to their questions.

4. I recommend useful links or reference information to others who are in need.

5. I facilitate the discussion processes in order to keep the thread on track.

Civic virtue

6. I actively participate in activities organized by the community.

7. I give up my personal time for some community-related stuff.

8. I keep abreast of changes in the community.

9. I keep myself updated with community announcements, posts, and so on.

10. I offer suggestions regarding how the community can improve.

11. I notify the community staff of potential problems.

Courtesy

12. I maintain a reasonable tone, even in unreasonable circumstances.

13. I show my appreciation for any input that other community members' contribute when asking for advice.

14. I respect other members' views and beliefs even if I do not agree with them.

15. I consider the impact of my action on other community members.

16. I obey the community policies.

Loyalty

17. I recommend this community to others outside the virtual community.

18. I generally say good things about this community.

19. I rate this community as superior to other alternatives.

Table 2. Items for Affective Commitment Scale

I identify myself as a member of this community.

I believe in the values embedded in this community.

This forum has a great deal of personal meaning for me.

I really feel as if this forum's problems are my own.

I do not feel like 'part of the family' in this forum. (R)

I do not feel 'emotionally attached' to this forum. (R)

I do not feel a strong sense of belonging to this forum. (R)

Note. $(\mathrm{R})=$ Reverse scored. Alpha $=.87$ 


\section{Results}

In the present study, we explored the means and standard deviations first. Then reliability analysis was conducted for each subscale of VCCB to examine the internal consistency of the items within each dimension. Last, we conducted correlation analysis to identify which hypothesis was supported in this study. The analyses are presented as follows.

\subsection{Descriptive Analysis}

First, we examined the mean and standard deviation for the measures. The Grad Cafe users indeed exhibit prevalent virtual community citizenship behaviors, as the means for each dimension of VCCB are around 5 on a seven-point Likert scale. Therefore, we can conclude members in The Grad Cafe are highly involved in community-oriented behaviors that promote the effective functioning of virtual community. Affective commitment towards this online forum exceeds 3 on a five-point Likert scale $(M=4.00$, $S D=0.83$ ), which suggests that most of the members in The Grad Cafe are emotionally attached to this forum. Please refer to Table 3 for descriptive statistics.

Table 3. Means of Subscales of VCCB and Affective Commitment Scale

\begin{tabular}{lccc}
\hline & $N$ & Mean & $S D$ \\
\hline VCCB & 52 & 5.33 & 0.75 \\
$\quad$ Altruism & 53 & 5.74 & 0.99 \\
Civic Virtue & 52 & 4.30 & 1.25 \\
$\quad$ Courtesy & 53 & 5.93 & 0.87 \\
$\quad$ Loyalty & 53 & 5.79 & 1.05 \\
Affective Commitment & 54 & 4.00 & 0.83 \\
How long have you been & 54 & 3.15 & 2.00 \\
in the forum? (years) & & & 1.62 \\
$\begin{array}{l}\text { How many friends do you } \\
\text { have in the forum? }\end{array}$ & 53 & & \\
\hline
\end{tabular}

\subsection{Reliability Analysis}

Next, we examined the Cronbach alpha for each subscale and found that all were reasonably reliable. Please refer to Table 4 for the statistics of Cronbach's $\alpha$ of each scale.

Table 4. Cronbach's Alpha Coefficients for Each Scale

\begin{tabular}{lc}
\hline & Cronbach's $\alpha$ \\
\hline Altruism & .87 \\
Civic Virtue & .83 \\
Courtesy & .84 \\
Loyalty & .78 \\
\hline
\end{tabular}

\subsection{Correlation Analysis}

Last, we conducted correlation analysis. Consistent with hypothesis 1 , we found that the higher a member's level of affective commitment, the higher the member's willingness to 
engage in virtual community citizenship behaviors will be $(r(52)=.72, p<.01)$. Affective commitment was significantly related to all the subscales of VCCB.

Correlations testing hypotheses 2 and 3 did not reach traditional levels of significance. As shown in Table 5, the correlation between social embeddedness and VCCB was $r(51)=.26, p<.07$. The correlation between tenure and VCCB was $r$ (52) $=.26, p<.07$. Please refer to Table 5 for further statistics.

Table 5. Correlations among Subscales of VCCB and Predictors

\begin{tabular}{|c|c|c|c|c|c|c|c|c|c|}
\hline & Scale & 1 & 2 & 3 & 4 & 5 & 6 & 7 & 8 \\
\hline 1. & VCCB & 1 & $.68^{* *}$ & $.83^{* *}$ & $.62^{* * *}$ & $.63^{* *}$ & $.72^{* *}$ & .26 & .26 \\
\hline 2. & Altruism & & 1 & $.45^{* *}$ & .22 & .15 & $.39^{* *}$ & .15 & .18 \\
\hline 3. & Civic virtue & & & 1 & .22 & $.38^{* *}$ & $.61^{* *}$ & .19 & .23 \\
\hline 4. & Courtesy & & & & 1 & $.55^{* *}$ & $.43^{* *}$ & .23 & .17 \\
\hline 5. & Loyalty & & & & & 1 & $.65^{* *}$ & .10 & .16 \\
\hline 6. & $\begin{array}{l}\text { Affective } \\
\text { commitment }\end{array}$ & & & & & & 1 & .20 & .22 \\
\hline 7. & Tenure & & & & & & & 1 & $.47^{* *}$ \\
\hline 8. & $\begin{array}{l}\text { Social } \\
\text { embeddedness }\end{array}$ & & & & & & & & 1 \\
\hline
\end{tabular}

Correlation significant at the $p<0.01$ level (2-tailed).

\section{Discussion}

We created a measure of virtual community citizenship behavior based on critical incidents of citizenship behaviors drawn across a variety of virtual communities. We found four subscales or facets of citizenship: altruism, civic virtue, courtesy and loyalty. These dimensions blend the dimensions from Kang et al. (2007) and Organ (1988) citizenship taxonomies. Surprisingly, we did not find a sportsmanship dimension.

The results of the analysis suggest that community members who identify with, and are emotionally attached to the community, are more likely to engage in virtual community citizenship behaviors than members who are not emotionally attached. There are several features of The Grad Cafe that may contribute to the significant predictive relationship between affective commitment and the willingness to engage in virtual community citizenship behaviors. Normally, forum signatures only appear on the profile pages of a community member without popping up on the homepage. Unlike the other forums, The Grad Cafe has a feature that promotes the forum signature share by putting information on the homepage once members update their signatures, which makes it 
easier for the community members to respond to others' emotional expression. The signatures in The Grad Cafe tend to serve as an outlet for community members to release the pressure and frustration they encountered when applying for graduate schools. Sometimes, community members use the signature to express their joyful moments after they are admitted to a grad school. Therefore, the automatic signature update pop-up on the homepage really makes a difference in terms of fostering the interaction among community members and accelerating the fulfillment of socio-emotional needs. Based on the analysis, the owners or managers of a virtual community should put more efforts on creating an environment where community members enjoy "hanging out" with each other.

\subsection{Limitations}

The results show that the means of virtual community citizenship behaviors are relatively high, which suggests the members in The Grad Cafe are highly involved in helping behaviors and prosocial behaviors. One of the reasons might be due to the fact that those who complete surveys will naturally score higher on VCCB because completing surveys for another member indicated a form of virtual community citizenship behavior. Considering this, it would be desirable to collect more data and include more members who are less active in the forum.

The results regarding the VCCB measure suggest that most of the items within a given dimension are highly inter-correlated and they may indeed measure the same underlying unidimensional construct. For this reason, it can be concluded that the majority of the items in the VCCB measure can be retained for further study. However, more data needs to be collected in order to see whether the items on each subscale conform to the hypothesized dimensions.

In this study, the results of the correlational analyses fail to prove that structural embeddedness and membership tenure positively influence the willingness to engage in virtual community citizenship behaviors. However, the sample size of this study is small which imposes constraints on the possible significant relationships between the predictors and the outcome variable. In addition, the majority of The Grad Cafe users are students who need help to get through the difficulties of applying to grad school and they tend to be actively involved in this forum when going through the application process. However, after they have completed their applications, they become less active. For this reason, it is hard to predict how willing members are to engage in virtual community citizenship behaviors based on their membership tenure. Hence, it would be more accurate to retest the hypothesized positive relationships between the predictors and the outcome variable when more participants are available. Although our predictions regarding tenure and social embeddedness were not supported, the correlations are promising and warrant further research.

Since this study is conducted in an online forum focused on the students applying for graduate schools, the generalizability of the results of this study remains to be tested. There are a variety of online forums depending on the focus of the discussion topic. The attempt of future study can be placed on implementing similar studies in other online communities. In this study, we developed a measure assessing VCCB and explored the antecedents of virtual community citizenship behaviors. Certainly more works needs to be done. We did not have enough participants in the study to adequately perform a factor analysis or test the paths. 


\subsection{Theoretical Framework}

Figure 1 is a structural model road map for research on VCCB. The model includes component there were tested in this study (solid lines) and components that were mentioned or tested by researchers in similar studies (dotted lines). As is evident, there are interesting possibilities in the study of virtual community citizenship behavior. For instance, in this study, loyalty included a set of behaviors involving broadcasting the benefits of the community to others. Is loyalty a component of citizenship or a component of affective commitment? Similarly, the measure of affective commitment used in this study had a strong personal identity component. Aside from one item in the subscale, there was little reference to actual emotional attachment. Do the two function independently? Further, is sportsmanship an appropriate category for citizenship in a virtual community? Is conscientiousness different from civic virtue in a virtual community? In addition, this study could have included a better measure of social embeddedness and could have borrowed constructs from the research by $\mathrm{Yu}$ and $\mathrm{Chu}$ (2007) including cohesiveness and affection similarity. Researchers who want to build a comprehensive model of VCCB need to include a more comprehensive measure of social embeddedness. There is more work to be done.

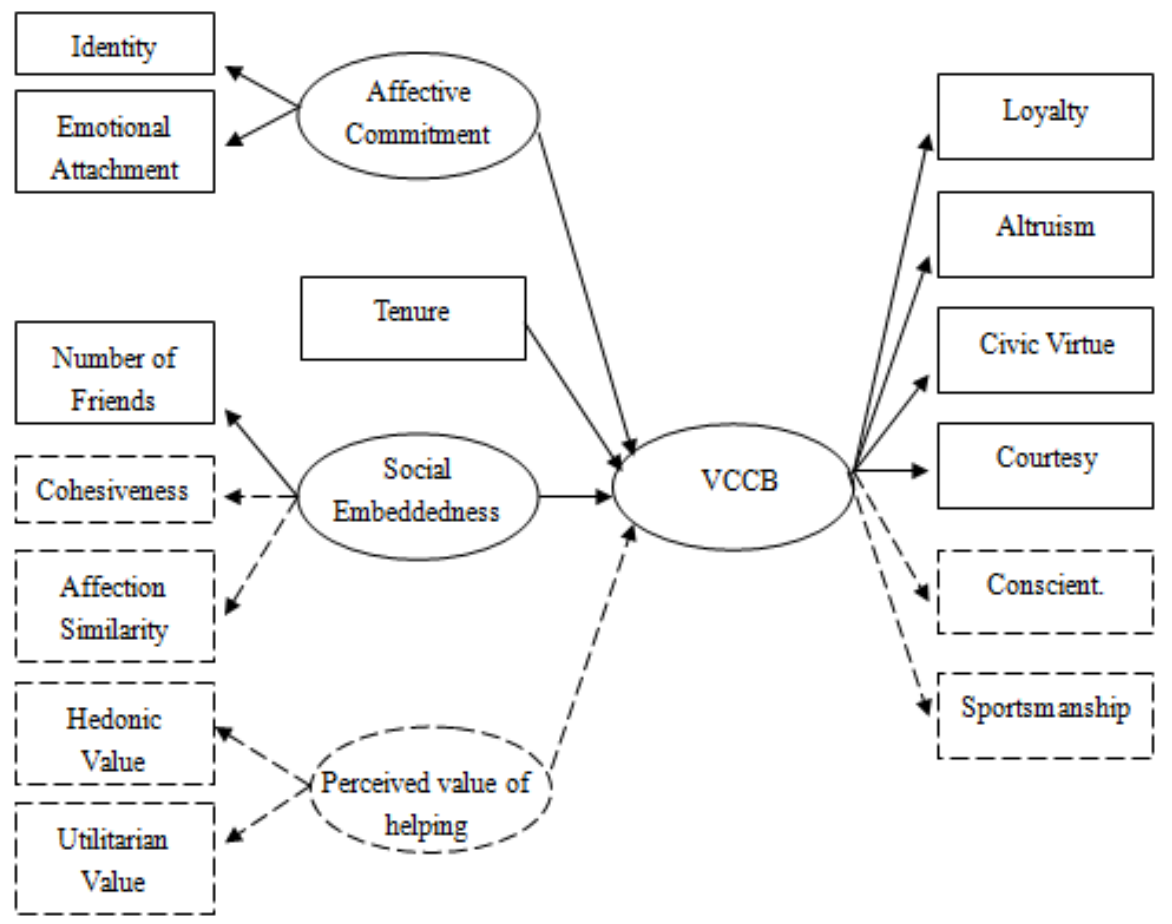

Figure 1. Model of virtual community citizenship behaviour 


\section{References}

1. Allen, N.J., \& Meyer, J.P. (1990). The measurement and antecedents of affective, continuance and normative commitment to the organization. Journal of Occupational Psychology, 63(1),1-18.

2. Barnard, C.I. (1938). The Functions of the Executive. Cambridge, MA: Harvard University Press.

3. Bateman J.P., Gray H.P., \& Butler S.B. (2006). Community commitment: how affect, obligation and necessity drive online behaviors. Twenty-Seventh International Conference on Information Systems, Milwaukee.

4. Boetcher, S., Duggan, H., \& White, N. (2002). What is a virtual community and why would you ever need one? Retrieved from http://www.fullcirc.com/community/communitywhatwhy.htm.

5. Brief. A.P., \& Motowidlo. S.J. (1986). Prosocial organizational behaviors. Academy of Management Review, 11, 710-725

6. Chiu C.M., Wang T.G., \& Fang Y.H. (2009). Antecedents of citizenship behavior in open professional virtual communities. PACIS 2009 Proceedings. 8.

7. Donath, J.S. (1996). Inhabiting the virtual city - the design of social environments for electronic communities. Cambridge, MA: MIT Press.

8. Kang, I., Lee, K., Lee, S., \& Choi, J. (2007). Investigation of online community voluntary behavior using cognitive map. Computers in Human Behavior, 23, 111126

9. Katz, D. (1964). The motivational basis of organizational behavior, Behavioral Science, 9, 131-146.

10. Lave, J., \& Wenger, E. (1991) Situated Learning: legitimate peripheral participation. Cambridge: Cambridge University Press.

11. LePine, J.A., Erez, A., \& Johnson, D.E. (2002). The nature and dimensionality of organizational citizenship behavior: a critical review and meta-analysis. Journal of Applied Psychology, 87(1), 52-65.

12. Li, D., Browne, G.J., \& Wetherbe, J.C. (2006). Why Do Internet Users Stick with a Specific Web Site? A Relationship Perspective. International Journal of Electronic Commerce, 10(4), 105-141.

13. Meyer, J.P., \& Allen, N.J. (1997). Commitment in the workplace: Theory, research, and application. Thousand Oaks, CA: Sage Publications.

14. Nahapiet, J., \& Ghoshal, S. (1998). Social capital, intellectual capital and the organizational advantage. Academy of Management Review, 38(2), 242-266.

15. Nonnecke, B., \& Preece, J. (1999). Shedding light on lurkers in online communities. Paper presented at the Ethnographic Studies in Real and Virtual Environments: Inhabited Information Spaces and Connected Communities, Edinburgh.

16. Oded, N., \& Chen, Y. (2008), Community photo sharing: motivational and structural antecedents. ICIS 2008 Proceedings. 91.

17. Organ, D.W. (1988). Organizational citizenship behavior: the good soldier syndrome. Lexington, MA: Lexington Books.

18. Organ, D.W., \& Ryan, K. (1995). A meta-analytic review of attitudinal and dispositional predictors of organizational citizenship behavior. Personnel Psychology, 48, 775-803. 
19. Organ, D.W. (1997). Organizational citizenship behavior: It's construct clean-up time. Human Performance, 10, 85-97.

20. Pettit, T., Donohue, R., \& Cieri, D.H. (2003), Career stage, organizational commitment and organizational citizenship behavior. Paper presented at Australian and New Zealand Academy of Management 17th anuual Conference. Retrieved from http://www.buseco.monash.edu.au/mgt/research/working-papers/2004/wp5804.pdf.

21. Rheingold, H. (2000). The virtual community: homesteading on the electronic frontier (Rev. ed.). Cambridge, MA: MIT Press.

22. Rogers, E.M., \& Kincaid, D.L. (1981). Communication networks: toward a new paradigm for research. New York: Free Press.

23. Schappe, S. (1998). Understanding employee job satisfaction: the importance of procedural and distributive justice. Journal of Business and Psychology. 12 (4), 493-503.

24. Wasko, M., \& Faraj, S. (2005). Why should I share? Examining knowledge contribution in electronic networks of practice. MIS Quarterly 29 (1), 1-23.

25. Wiertz. C., Ruyter, K.D., \& Streukens, S. (2003). On the role of normative influences in commercial virtual communities. Retrieved from http://edocs.ub.unimaas.nl/loader/file.asp?id=788.

26. Yeow, A., Johnson, L.S., \& Faraj, S. (2006), Lurking: legitimate or illegitimate peripheral participation? Paper presented at the 27th International Conference on Information Systems, Milwaukee.

27. Yu, C.P., \& Chu, T.H. (2007). Exploring knowledge contribution from an OCB perspective. Information \& Management, 44, 321-331. 